\title{
SUSTAINING PLACE-IDENTITY IN HISTORIC MINING CITIES OF THE US ROCKY MOUNTAIN WEST
}

\author{
WENDY R. MCCLURE \\ College of Art and Architecture, University of Idaho, USA.
}

\begin{abstract}
In the case of 19th century mining towns, inherited morphology as exhibited in residual layers of urban (built) fabric provides a tangible connection to authentic mining culture amidst the current era of development and change. This paper will discuss the relative successes of varying approaches to preserving mining-era morphology of two former silver mining towns that have been adapted as bustling downhill skiing and recreational amenity towns. Planning and preservation strategies used to guide development in Park City, Utah, will be compared with policies guiding development in Telluride, Colorado, which enjoys National Landmark status. Each town has taken a different view of its cultural heritage and is guided by different principles concerning adaptation and preservation of inherited context. Philosophical differences inherent to planning policy and preservation guidelines are clearly legible in each community's respective urban form. Resulting loss of historic continuity and regional identity suggests a need for a deeper interpretation of authenticity than is afforded by most policies guiding community development and historic preservation.
\end{abstract}

Keywords: Design guidelines authenticity, historic preservation, mining heritage, place-identity, urban morphology.

\section{INTRODUCTION}

Sustaining place-identity in former 19th century silver mining cities in the Rocky Mountain region of the United States can be challenging given the major shifts in economic purpose and population that have occurred since the mining era. In most cases, mining populations who shaped the signature character of mining cities diminished during the second half of the 20th century in tandem with each cycle of fluctuating silver prices. Population loss through waves of mass ex-migration or gradual decline left entire communities in a state of near abandonment. Residents who remained sought avenues for renewed economic purpose based on recreational opportunities afforded by surrounding mountain resources and re-purposing their unique mining contexts. Cities that have successfully constructed 'new west' economies have developed industries and businesses that cater to tourism, downhill skiing and mountain recreation. Immigrants of the 'new west' economy come in many forms, including outdoor enthusiasts, real estate developers, land speculators, business owners and community builders. This paper will discuss the critical role that urban morphology can play in helping to define, interpret, and preserve placeidentity in historic mining cities. Telluride, Colorado, and Park City, Utah, will be used as case studies to compare relative capacity to sustain legibility of mining-era contexts in the face of contemporary growth and development. Telluride, enjoys national landmark status and Park City heralds two national historic districts in its historic 'Old Town.' Mining-era contexts have been adapted as centres for tourism, mountain recreation and downhill skiing. Mining heritage plays a central role in their branding and marketing plans. Each community's ability to sustain placeidentity and a tangible connection to authentic mining culture through periods of economic realignment has depended in part upon the quality of principles and practices used to guide growth and development. In the case of mining cities, how can an understanding of mining-era morphology be used to strengthen capacity to preserve place-identity in the face of contemporary development? 


\section{MINING-ERA DEVELOPMENT CONTEXT}

A brief discussion of key influences that helped to shape each community's physical urban form during the mining era follows. Highlights include geographic setting, a century of corporate mining economy and culture, railroad transportation and town planning practices.

\subsection{Economic Influences}

Silver mining dominated the economies of Telluride and Park City for 80-100 years providing ample time for mining culture and operations to exert a deep imprint on the urban forms and fragile mountain landscapes. Discovery of lode silver deposits and cultivation of corporate mining afforded sustained periods for economic growth allowing multiple generations to participate in processes for building, shaping and polluting built and natural environments. At their peaks, Telluride and Park City boasted populations of approximately 6000 and 10,000, respectively. Contrary to historic accounts of mining communities as unplanned, spontaneous, and temporary settlements, both towns established a sense of permanence by the 1890s. Immigrants who were lured by long-term employment opportunities invested in community building processes as evidenced in remaining commercial districts, civic buildings and residential neighbourhoods.

\subsection{Geographic Influences}

Natural geography played a major role in shaping urban form in Telluride and Park City. Both cities are sited within steeply sided canyons that are formed by surrounding mountain ranges. Steep topography historically served to confine development and define city edges during the mining era. The 19 th and early 20th century portions of their city plans feature gridded configurations of interconnected streets, blocks and alleys. Town plans were platted as a gridded network of streets and bisected by a spinal main street. Growth was accommodated through a configuration of additions that were elongated along the canyon axis. Their main streets aligned the path of extraction, linking central business districts to the flow of ore from mining operations at canyon heads and leading to principle transportation routes at canyon openings. A brief summary of defining characteristics specific to each town's morphology follows.

\subsection{Formative Planning Influences}

Telluride occupies the most dramatic alpine setting with peaks rising to $4267 \mathrm{~m}$ (14,000 feet) on three sides (see Fig. 1). The town's glacial box canyon spanning almost $1 / 2$ mile across gently sloping terrain accommodated platting of the original town plan as an equal sided square. Severe Rocky Mountain winters commanded a need for a compact, easily negotiated town plan and optimal solar orientation. Both needs appear to have been important considerations in defining Telluride's town plan, especially in wealthier neighbourhoods. A grid network of streets and alleys divided the original plat into blocks that are nearly square in proportion and relatively compact at $76 \times 79 \mathrm{~m}$ $(250 \times 260$ feet $)$ affording maximum connectivity [1]. Colorado Avenue, Telluride's Main Street is boasted to have been wide enough for a 'team of 6-8 oxen to turn around without difficulty' [2] (Fig. 2). The overall plat was informally segregated by use and economic class. Telluride was sufficiently isolated from urban settings that mining company management resided there year round. Wealthier residents mitigated the effects of severe Rocky Mountain winters by situating homes and businesses favourably to capture sunlight and views afforded by the town's south-facing, gently sloping canyon floor. Industrial land uses and residential neighbourhoods for mine workers and 


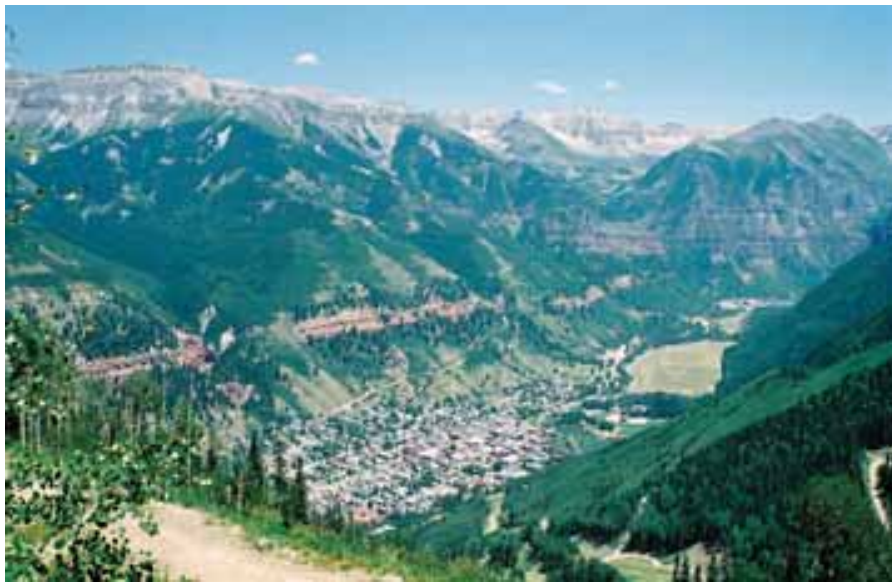

Figure 1: Town view of Telluride, CO showing box canyon.

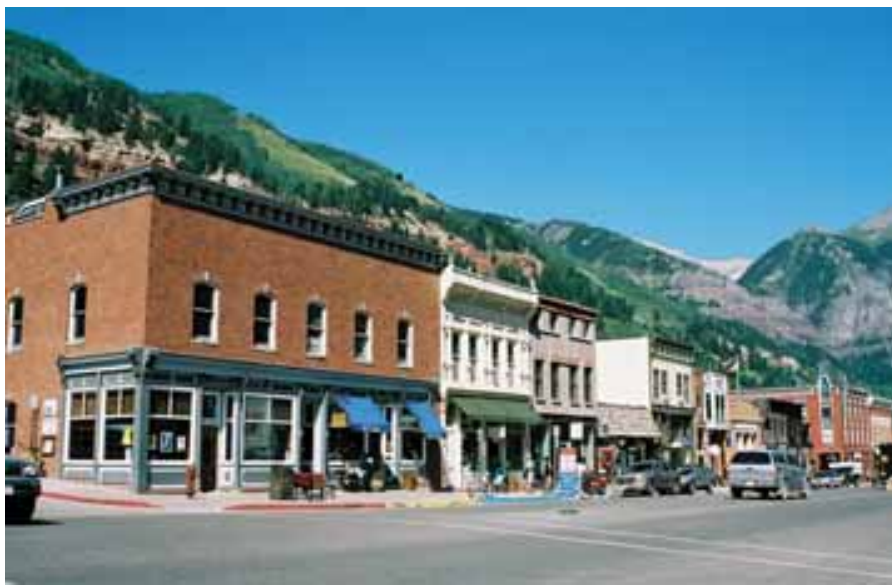

Figure 2: Colorado Avenue, Telluride, CO.

prostitutes were cloistered in the lower shadows of the north-facing side of the canyon along the east-west flowing San Miguel River [2].

In the earliest residential neighbourhoods, orientation of residential building lots and house construction along an east-west axis most likely reflects the desire to minimize grade issues while maximizing the number of opportunities to access coveted southern exposure. Plot patterns in the commercial core along Colorado Avenue shift at mid block to a north-south axis to maximize opportunities for exposure of storefronts along main streets. Commercial blocks are subdivided by a T-shape alley system, which affords access at the rear of commercial buildings in addition to the rear of residential parcels. Community growth was supported through successive platted additions, which linked into original network of streets and alleys. In 1891, the Rio Grande Southern Railroad platted a western addition consisting of blocks and a bisecting alley system that are elongated to the east and west to parallel the railroad line (see Fig. 3). Parcels are narrow and oriented elongated 


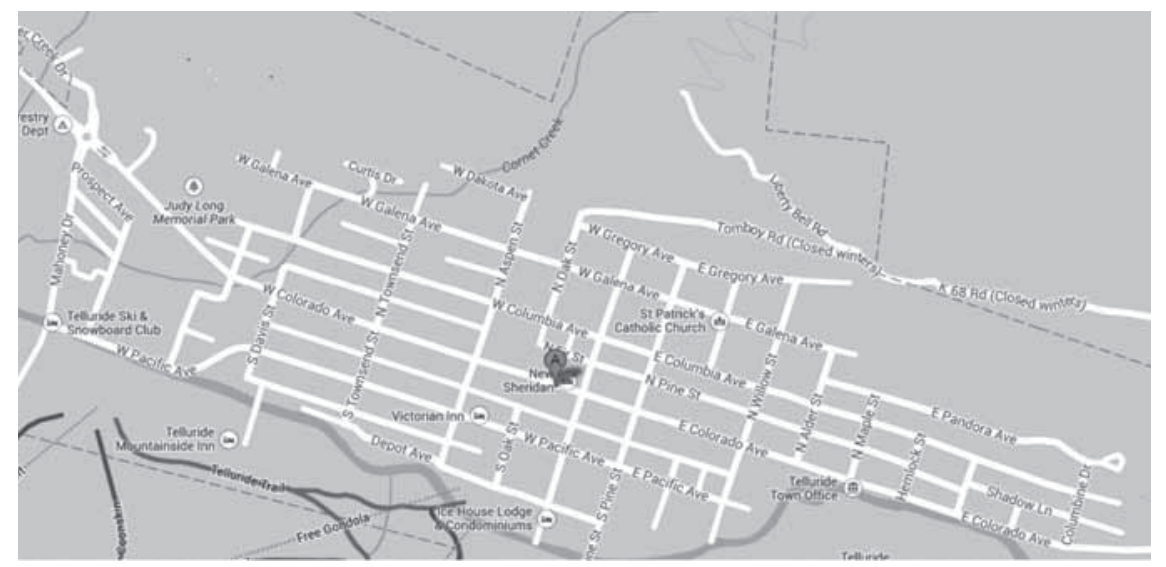

Figure 3: City map of Telluride, $\mathrm{CO}<\mathrm{https} / /$ maps.Google.com $>$.

north-south, exactly the opposite of the original plat. Houses for mine and railroad labourers were small and simple in design with gable ends facing the street. Land in the railroad plat was treated more as a commodity than a template for community building. Unlike the original town plan, which gave thoughtful consideration to climate and quality of life in its orientation and configuration of blocks, efficiency and profit appear to have been the dominating planning ideas in the railroad's addition.

Park City is sited in a narrow V-shaped canyon measuring less than $152 \mathrm{~m}$ (500 feet) across. The town originally formed in 1870 as a mining camp along the canyon floor, which stretches for about 1 mile along a north-south axis. The original town site was located at the head of the canyon. Constricting topographic conditions prevented Park City's original plat from accommodating a regularly sized block or parcel patterns, especially at the canyon head where streets converged. Only four to five paralleling streets could be accommodated along the flanking slopes with a single, bisecting main street at the lowest point of the sloping canyon floor. Blocks were long and irregular in length (approximately 129.5-137.2 m) (425-450 feet). Blocks along the main commercial streets were generally a single lot in depth. Typical of many mining settlements, miners' housing was located above the canyon floor on steeply sloping terrain. Two room residences were arranged in paralleling rows and connected to town through a series of wooden steps in place of city streets. Residential lots in the historic core of town were typically $7.6 \times 23 \mathrm{~m}(25 \times 75$ feet $)$, which encouraged compact development. The historic housing stock featured an assortment of simple, late 19th century, small footprint house designs. Park City did not develop upscale neighbourhoods because mine owners chose to live in nearby Salt Lake City (Figs 4 \& 5).

\section{ECONOMIC DECLINE AND TRANSITION}

Cycles for settlement, economic growth and decline in both communities mirrored trends in national silver markets. Depressed silver prices after World War II caused instability in corporate operations leading to high unemployment, ex-migration of mining populations and eventual cessation of mining operations in mining towns throughout the western US [3]. Telluride and Park City were not immune. Corporate mining operations ceased in Telluride in the 1950s and Park City in the 1970s. Both communities achieved 'ghost town' status as their mining populations plummeted. Arguably, each town's unique built environment came to represent the only tangible link to 'authentic' mining 


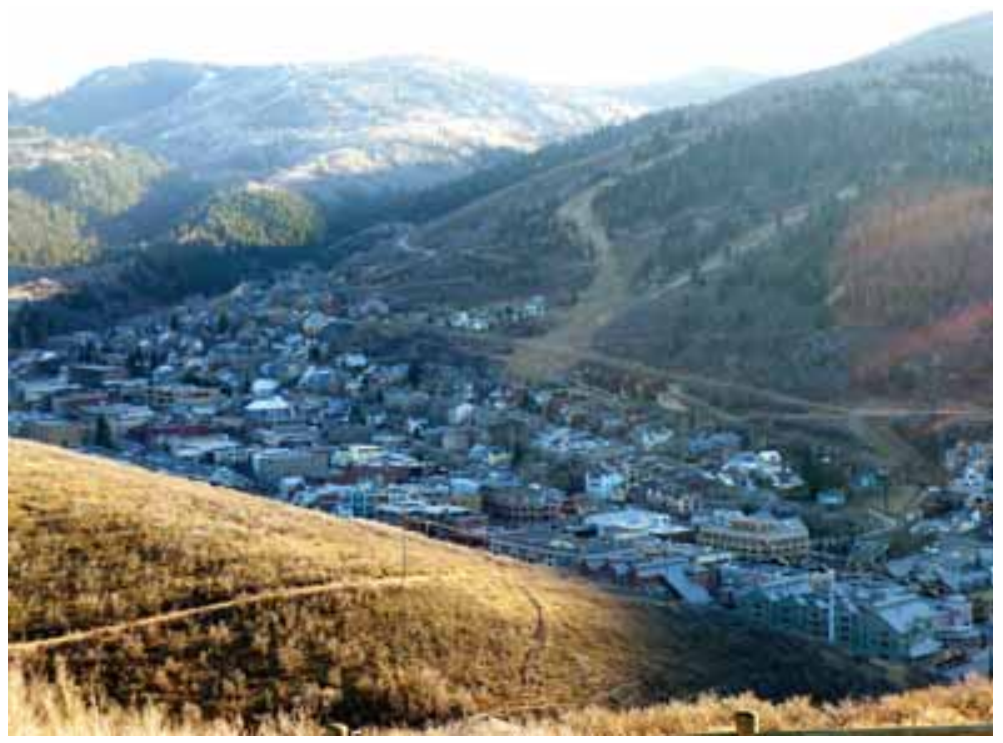

Figure 4: Town view of Park City, Utah.

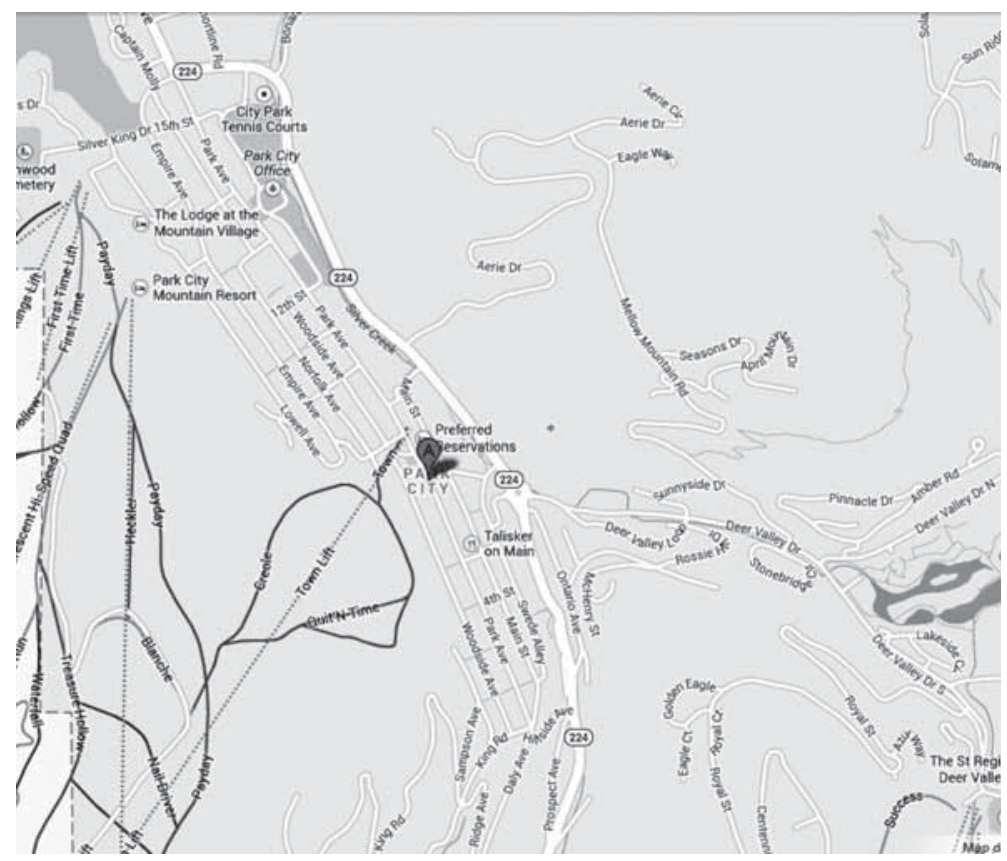

Figure 5: Partial map of Park City, Utah $<$ https//maps.Google.com>. 
heritage. Mining-era housing and commercial structures persisted in a state of preservation by neglect while those who remained sought avenues for economic diversification.

The mountainous settings of both communities enabled them to transition to service economies based on downhill skiing and mountain recreation. Downhill skiing, ironically, is not inconsistent with mining culture. Early 20th century, archival photographs depict miners in Park City using skis and broom stick poles for winter travel between communities. Beginning in the 1920s, local citizens in Park City enjoyed back country ski outings. Prior to any ski area development, locals commandeered mining company trams to transport skiers. In 1968, corporate attorney Joe Zoline initiated development of a European style ski resort in Telluride. A new urbanist before his time, Zoline objected to Aspen's sprawling development and recognized that Telluride's unique morphology could support his vision of a compact European style ski area connected to a revitalized town [4]. Similarly, Aspen-based developer, Edger Stern, helped to launch a European style ski area in Park City by developing a lift base along Main Street to transport skiers to the mountaintop. Ski industries in both communities continue on an upward trajectory, with the help of wealthy investors. They retain a direct link to town centres.

\section{CONTEMPORARY DEVELOPMENT CONTEXT}

How effectively has each city been in sustaining its unique inherited mining-era morphology and associated place-identity in the face of economic change? Have planning policies and regulations guiding development achieved quality integration between inherited mining-era contexts and contemporary, upscale ski-related development? A comparison of policies, past and present, guiding late 20th and early 21 st century historic preservation and recreation era development follows.

\subsection{Telluride's Planning and Preservation Policies}

In 1963 Telluride was granted national landmark status, which constitutes the highest level of recognition afforded by the US Secretary of Interior for historic places. Landmark designation has contributed to the city's heightened level of awareness about the value of its historic resources and led to the implementation of protective regulations. In 1974, Telluride created an historic preservation zone, which encompassed the entire town and required design review of all construction projects within city limits. Boundaries of the local landmark district were later adjusted to protect historic integrity within mining-era neighbourhoods and to encourage development outside of the landmark district to remain 'compatible in scale and character with mining-era heritage' [5]. To help forward these goals, the planning firm Winter and Associates was contracted in 1997 to create comprehensive design guidelines that embrace the entire mining-era context including commercial, residential and industrial areas as well as urban design standards for new ski-related development neighbourhoods.

A majority of standards regulating development in US historic districts focus on the use of architectural standards to encourage appropriate preservation practices and new infill construction. By contrast, Telluride's guidelines address multiple dimensions of the built environment including architecture, planning patterns, land use and urban design character. Capacity to preserve clarity of inherited mining-era urban form is enhanced because they acknowledge the critical role that historic planning patterns play in defining place-identity. They seek to protect the legibility of underlying structure of historic urban form, including the inherited town plans' signature elements - its gridded configuration of streets, rectangularity of parcels, orientation of buildings, and building typologies. New infill construction and additions to historic structures must reinforce inherited planning patterns including relationships to adjacent buildings, orientation to parcels, blocks and street grid; building 
rehabilitations and adaptations must conserve historic integrity and scale that is consistent with the mining era (Fig. 6).

Telluride's guidelines also seek to preserve and enhance the uniqueness of each of its historic neighbourhoods and their associated scale, spatial characteristics, building typologies, and land uses. A regulating master plan divides the city into treatment areas. Each treatment area is bound to guidelines that are specifically tailored to protect its inherited spatial characteristics and building typologies. In the spirit of early form-based codes, each treatment area specifies allowable building typologies associated with historic uses. The 'Warehouse Treatment Area,' which is the most diverse, was originally characterized by an eclectic mix of railroad uses, industrial buildings, boarding houses and miner's cribs. Today the warehouse district is challenged by the need to accommodate significant changes in land use. The area's inherited mixture of building typologies and uses afford the greatest design flexibility to accommodate both small and larger scale infill projects. Large footprint multi-family housing and mixed use projects have been successfully integrated in the Warehouse Treatment Area where historic industrial uses establish a precedent for larger scale buildings [6] (Figs $7 \& 8$ ).

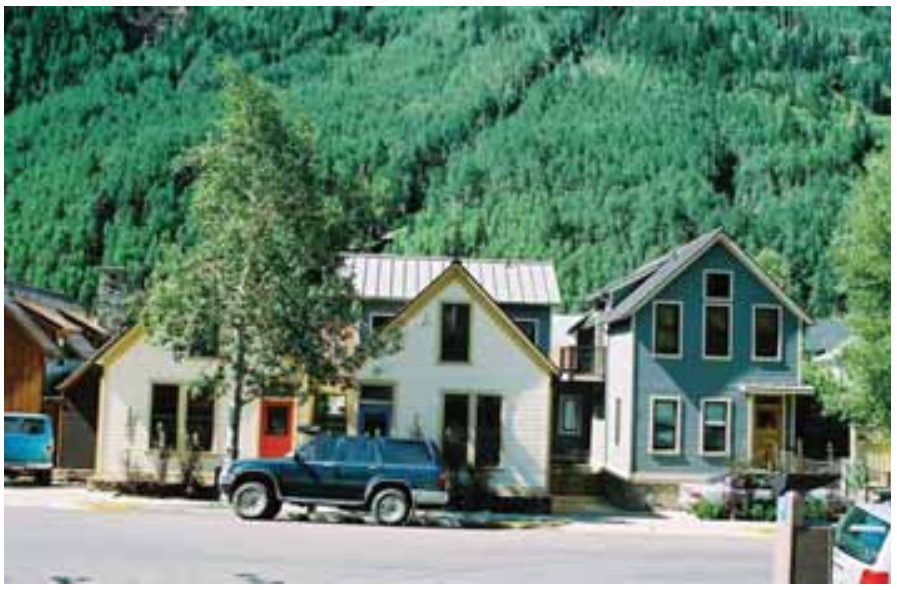

Figure 6: Compatible infill housing Telluride, CO.

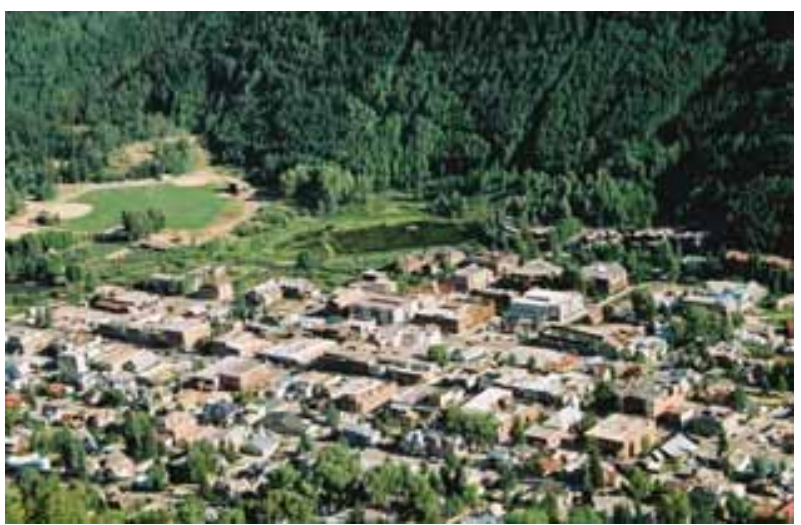

Figure 7: Warehouse Treatment Area. 


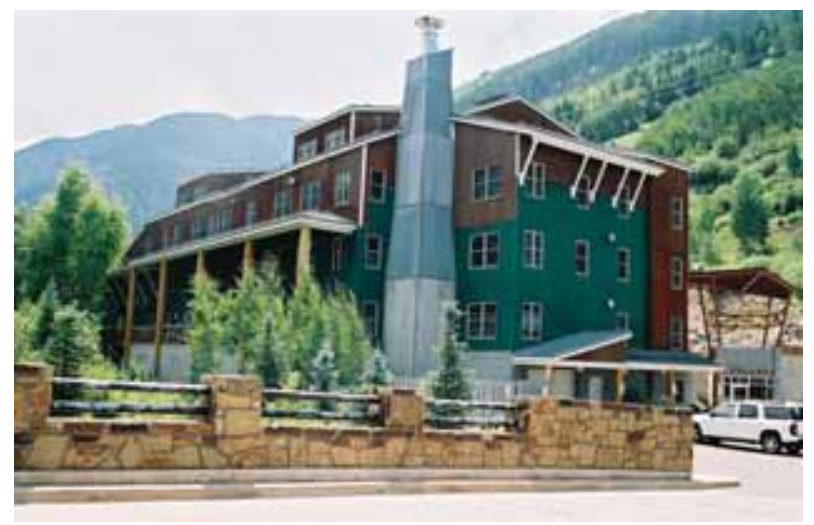

Figure 8: New construction in historic Warehouse Treatment Area.

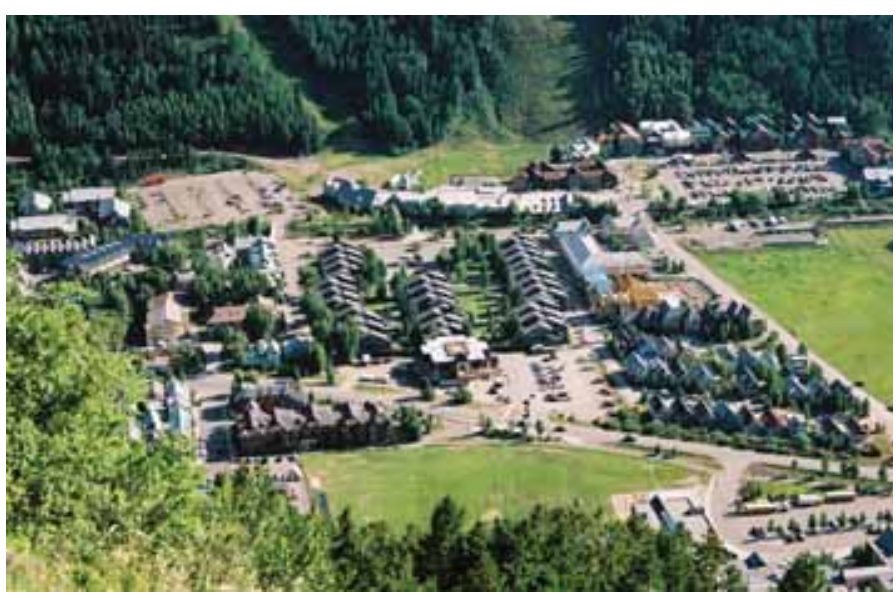

Figure 9: 'Ghost of town grid' in new Accommodations Area.

A breakdown in morphological continuity occurs at the intersection between historic treatment areas and the 'Accommodations Treatment Area,' a contemporary district that houses large skioriented condominium developments. As viewed from atop canyon walls, new developments undermine clarity of the inherited town plan. While the guidelines encourage 'preservation of the ghost of the street grid' in all areas of the canyon floor, in reality the grid's legibility is largely obscured by large bands of development, which undermine visual and physical continuity. The guidelines point out that 'individual projects, with separate identities, have failed to establish an overall sense of visual continuity.' 'As seen from a distance, the Accommodations Treatment Area should appear to be a part of the community, with essentially the same perceived street and alley arrangements, building forms and development scale' [7]. To address the reality of incompatible development, the guidelines should prescribe key elements of a healthy urban tissue. Urban morphologist MRG Conzen defined distinct legible urban patterns as 'plan units.' If new developments were regulated as part of a designated 'plan unit,' compatibility with inherited patterns could be achieved through prescriptive specifications for street systems, connectivity, and interstitial space [8, 9] (Fig. 9). 


\subsection{Park City's Planning and Preservation Policies}

Park City's 'Old Town' district was designated as two national historic districts in 1978. The importance of maintaining 'the unique identity and character of an historic community' [10] has been stated in General City Plan (master planning) documents since 1985. A commitment to 'promote a strong sense of place, character, and heritage' is reiterated in the city's most recent and soon to be adopted, 2013 General Plan [11]. Rapid community growth, real estate speculation and expansion between 1985 and 2008 have made these goals challenging to achieve. Prior to the 2008 recession, Park City experienced multiple years of booming development in concert with its rapidly expanding mountain recreation economy and role as host city for the 2002 winter Olympics. The city was largely unprepared for its decades of growth in part because the 1985 and updated 1993 General Plans were based on ambiguous, and somewhat conflicting, goals that supported multiple images of the community. Their inherent vagueness and inability was reflected in the introduction to the 1993 General Plan, which stated 'While the features of a community's character are difficult to define with precision ...' [10] Prior to 2009, Park City's General Plan supported multiple images of the community, including mining, rural ranching, and mountain resort, suggesting that the city was suffering from an identity crisis. While the General Plan reflected citizen's appreciation of the town's mining heritage and physical elements that contributed to 'a cultural sense of place,' it lacked an adequate spatial language to clearly define and interpret its mining-era context [10].

Historic preservation efforts in Park City have met with mixed success. Multiple blocks of commercial buildings along Main Street have been artfully restored to their former grandeur. However, just one block off of Main Street in the Old Town area, ski-related development pressures are overwhelming historic scale and integrity. New infill housing units dwarf nearby miners' cottages or overshadow them with large footprint additions, emblematic of the intense real estate market pressures being exerted on them. By contrast, Telluride's guidelines regulate additions to mining-era buildings to support intent of the Secretary of Interior's Standards. Some miners' cottages have been adapted as street scale fronts to multi-story, large footprint condominiums additions that compromise their historic integrity and scale. In extreme cases, historic structures have been partially deconstructed and reassembled as modules within new buildings. In fall 2007 during a site visit, it appeared that Park City's mining heritage was disappearing at an accelerating rate-one construction project at a time (Fig. 10).

As early as 1997, the General Plan recognized the importance of protecting the "natural and visual 'basin' defining the community and perceived scale of a town by allowing it 'to remain a distinct geographic place"” [10]. The reality is that development since 1997 has continued to infringe upon 'Old Town' allowing the image of an upscale recreation resort town to infiltrate its residential and commercial streetscapes. Vistas to open hillsides as viewed from 'Old Town,' once considered sacred by locals, now view a changing landscape comprises sprawling, recreation-related sub-divisions of the 'new west.' The transformative circumstances alarmed locals and city planning staff sufficiently to initiate a community visioning process in 2009 . Visioning served as a segue to creating a renewed General Plan for future development. A consensus view to 'preserve a strong sense of place, character, and heritage' emerged as a key goal [11]. Participants identified 'Historic Character' as one of four core values of Park City, emphasizing the importance mining heritage. Their vision articulates a commitment to 'preserve the integrity, scale, and historic fabric of the locally designated historic resources and districts for future generations' [11].

Park City's draft General Plan, released in March 2013, continues to reflect a degree of tension between economic development and preserving mining heritage identity as noted by the statement, 'Protecting the rich history of place while allowing continued reinvestment into the districts is a balancing act; one that is an ongoing challenge for residents and City leaders' [11]. The verdict is still out on the overall impact the plan will ultimately have on mining-era contexts. 


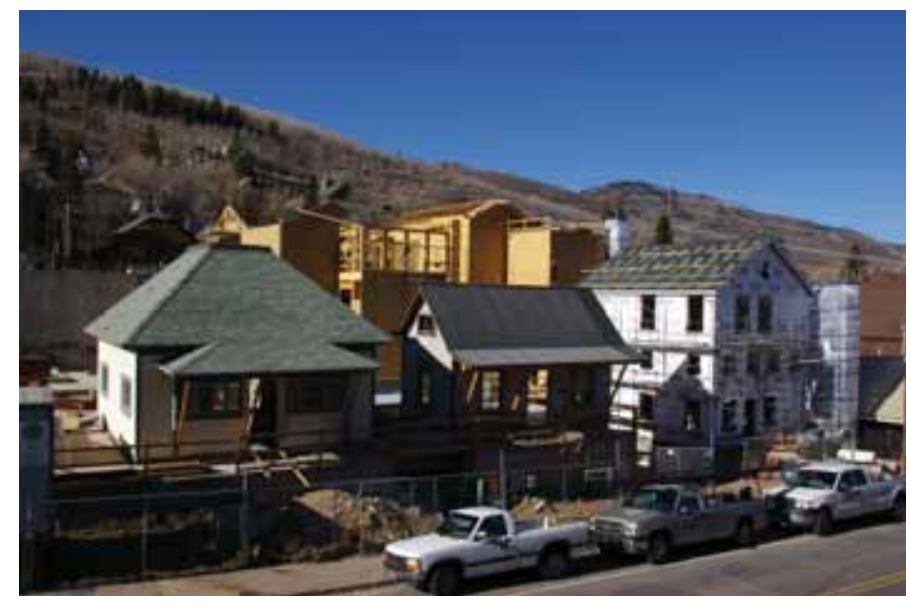

Figure 10: Changing housing scale in Park City, Utah.

Guidelines enacted in 2009 for the 'Old Town' historic districts seek to correct some inherent deficiencies in development standards affecting historic resources that were in place when the city's pre-recession development boom occurred. The guidelines represent a significant improvement because they target well-defined preservation goals and recommend practices that are based on the US Secretary of Interior's Standards for Historic Preservation. Their introduction seeks to clarify the important role that preserving inherited context plays in maintaining a tangible connection to mining heritage. 'In most cases, Historic Sites in Park City provide an understanding of the culture and lifestyle of the area's mining activity and early ski industry' [12]. The guidelines seek to protect historic mining-era buildings from demolition, encourage their adaptive use, and compatible new infill development. The guidelines' architectural focus addresses issues of mining-era style, scale, and materiality describing historic buildings as having 'simple design, modest scale, and modest height and constructed of natural building materials' [12]. Guidelines regulating new development in the historic core call for context-based design that is derived from 'the average size, scale, and bulk' of structures 'within a specified distance of new building site' [12].

In addition to setting architectural standards, the new guidelines also acknowledge the importance of preserving several signature mining-era planning patterns as captured in the following statements: 'The dense clustering of small residential structures built along terraces moving up the hillsides away from the commercial core is one of the most prominent features in early photographs of Park City. This development pattern is still an important feature of the community today' [12]. Unfortunately, the reality of contemporary development has already compromised the clarity of historic patterns, especially along the east canyon walls. Aggressive intervention is needed to regulate the scale of infill replacement houses that tower over remaining miner's cottages. Contemporary resortstyle trophy homes sprawl over canyon walls and hillsides onto recently constructed subdivisions, blurring the natural edges that once defined the historic town. Only the view from the canyon floor along Main Street retains a sense of enclosure once afforded the original town (Fig. 11).

Park City's Main Street sited at the base of the narrow sloping canyon floor is geographically and architecturally framed as a descending commercial corridor. This signature urban form is acknowledged in the 2009 guidelines. A sense of a descending main street is partially obscured by recent development, which levels rooftops. Mid-rise tourist accommodations at the lower end of Main 


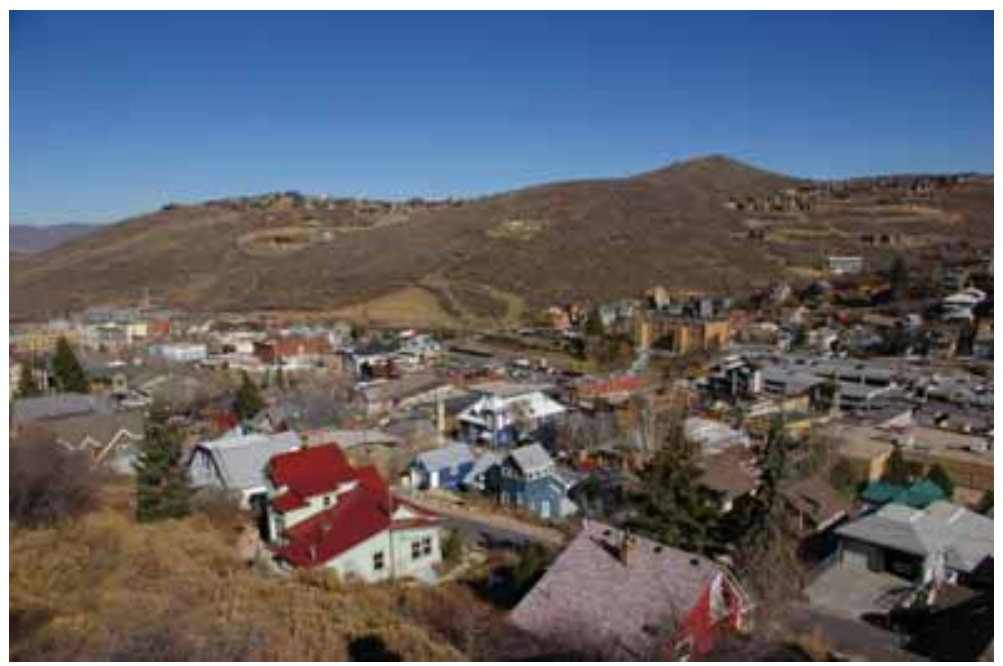

Figure 11: Overflowing canyon basin in Park City.

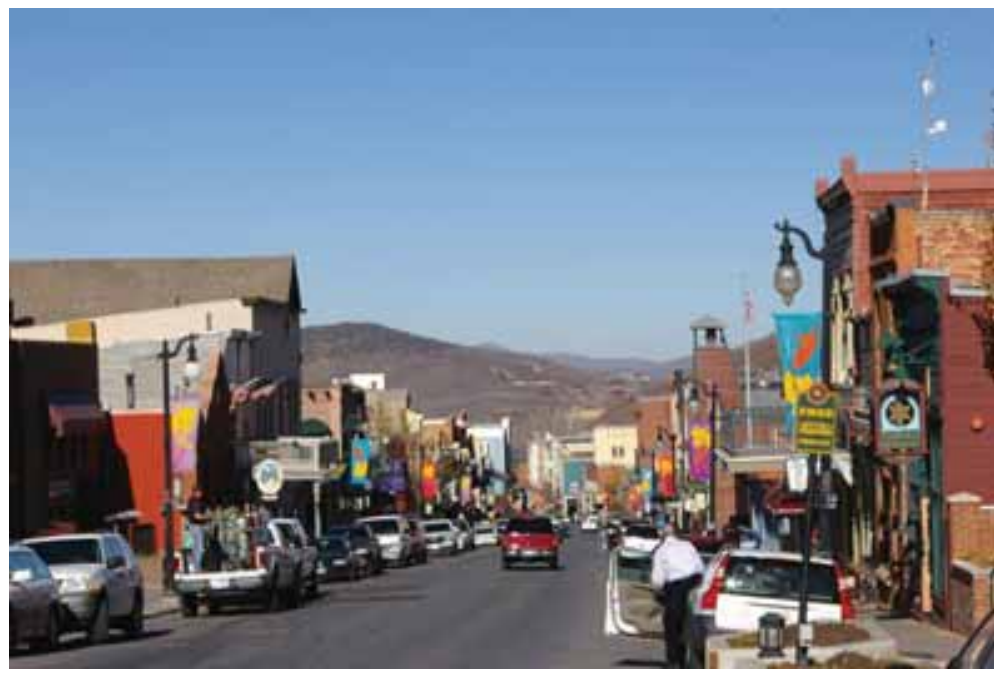

Figure 12: Descending Main Street in Park City.

Street depart from the established height to width ratios characterizing the narrower two-story historic commercial buildings located towards the canyon head. The most recent hotel accommodations located at the south end of Main Street near the town lift, arguably support mining town image and identity. Most are mixed use and reinforce the street wall. However, their four-story heights would overwhelm the one to two story historic commercial buildings if a descending Main Street did not help to mitigate perception of significant scale change along the street corridor. A potentially more effective approach to large footprint buildings might be to emulate the scale and form of mining-era building typologies, such as the simple rectilinear warehouse buildings and boarding houses (Fig. 12). 


\subsection{New Ski-Related Development}

Adaptations of the two historic mining towns as modern ski resorts exhibit varying capacities to successfully integrate mining-era fabric with contemporary ski resort development. At a planning scale, both cities have been successful at remaining compact and walkable. In both cities the decision to locate 'town' ski lifts within historic town fabric has proven to be instrumental in encouraging compact pedestrian-oriented development and important linkages to modern ski areas. A visible presence of ski lifts in downtown areas also reinforces the centrality of historic commercial districts, stimulates their economies and facilitates important linkages between tourist accommodations, residential neighbourhoods, and historic business districts. Guidelines prohibit auto-oriented business in the downtown area and encourage them to locate at the periphery of town, further protecting the compact nature of mining-era development and street character.

\section{CONCLUSION}

Reminiscent of previous generations, the communities of Park City and Telluride continue to attract new waves of fortune seekers in the form of land speculators and wild cat developers bent on exploiting natural and cultural resources. Consistent with previous centuries, each city is also supported by citizens, civic leaders and entrepreneurs who, as community builders are taking a longer term view of inherited resources. While few residents of either city retain any direct link to the mining industry, many are drawn to mining town ambience, which affords a strong sense of place-identity within remarkable recreational settings.

Given the intense economic pressures to transform inherited contexts in scale and character, each city's mining heritage remains at risk. As can be evidenced through field observation, Telluride has made significant progress in preserving signature mining-era elements and spatial characteristics relative to Park City. Both communities have met with mixed success in their capacities to assimilate new ski-related growth and development into their overall urban forms. Lessons learned from these two cases may be of use to other historic cities and towns as they develop planning policies. A brief summary of guiding principles follows.

1. Define key elements of the town plan. The urban morphology of historic contexts should be defined and interpreted as starting point for effective policy-making processes. A majority of guidelines for historic districts focus on preserving architectural facades, materiality and massing of individual buildings. By contrast, Telluride's approach to context preservation takes an expanded view by acknowledging the important role that the city's founding town plan plays in defining its historic context. Guidelines specifically address the importance of maintaining legibility of its gridded network of streets, blocks, lots, and alleys.

2. Reinforce historic neighbourhood patterns. New developments in historic neighbourhoods should strive to reinforce the legibility of inherited morphology. Telluride's guidelines require that new infill construction and additions conform to inherited urban patterns that help to distinguish each of its historic commercial and residential neighbourhoods. Spatial patterns are defined by the specifics of building orientation, setbacks, scale, and spacing for each city block.

3. Reinforce historic building typologies. Most cities use Euclidian zoning to regulate land use. Some communities have adopted form-based codes that prescribe appropriate building typologies. Telluride's guidelines constitute a hybrid. They divide the city into 'Treatment Areas' as defined by historic land uses and prescribe associated historic building types to serve as models for scale, materiality and form of new construction. Infill development in historic residential neighbourhoods is relatively compatible with historic house typologies. In the 'Warehouse 
Treatment Area', the guideline's intent is to afford an opportunity to absorb larger scale tourist accommodations and condominium developments into historic urban fabric. The reality is that large contemporary infill projects reflect the scale and massing of historic warehouses to varying degrees.

4. Preserve mining-era scale. Small-scale buildings and simple architecture are trademarks of most mining-era development. Mining-era scale remains legible in Telluride. Growth pressures in Park City are transforming and overwhelming historic fabric through over-scaled additions, facadism, and large footprint, multi-story infill construction. To preserve the mining era's spatial environment, scale should be rigorously regulated.

5. Preserve urban edges, density, and connectivity of inherited plan. A hiker's view of the enclosing canyon walls of both cities reveals that neither has been successful at integrating contemporary neighbourhoods with those of the mining era. Park City has permitted sprawling suburban patterns to surround its historic fabric and fray its city edges. Telluride's efforts to maintain 'the ghost of the city's historic grid' have been ineffectual.

Diligent stewardship and a deeper understanding of inherited morphology are needed to help guide more thoughtful community building processes in historic mining cities that have been adapted for mountain recreation. Inevitable growth and change should be guided by regulating plans and policies that address both preservation of defining elements of inherited urban fabric and their quality integration with contemporary development. A community's collective sense of self, today and in the future, is also critical to its ability to sustain place-identity.

\section{REFERENCES}

[1] Colman, R. \& McCoy, D., The R.G's Story, 2: Telluride, Pandora and the Mines Above, Sundance Publications: Denver, pp. 23-33, 2002.

[2] Fetter, R. \& Fetter, S., Telluride: From Pick to Powder, Caxton Press: Caldwell, pp. 24-26, 2001.

[3] Reps J., The Forgotten Frontier: Urban Planning and the American West University of Missouri Press: Columbia \& London, 1980.

[4] Fetter, R. \& Fetter, S., Telluride: From Pick to Powder, Caxton Press: Caldwell, pp. 161-173, 2001.

[5] Winter \& Company and The telluride community, Design Guidelines for Building in Telluride, Town of Telluride: Telluride, Colorado pp. IN-1-IN12, 1997.

[6] Winter \& Company and The telluride community, Design Guidelines for Building in Telluride, Town of Telluride: Telluride, Colorado pp. WC-1-WC-8, 1997.

[7] Winter \& Company and The telluride community, Design Guidelines for Building in Telluride, Town of Telluride: Telluride, Colorado pp. AC-1-AC-10 \&EWT-1-EWT-8, 1997.

[8] Moudon, A., Urban morphology as an emerging interdisciplinary field. Urban Morphology, 1(1), pp. 3-10, 1987.

[9] Conzen, M. (ed). Thinking About Urban Form: Papers on Urban Morphology 1932-1998, Peter Lang: Bern \& New York, p. 253, 2004.

[10] The Planning Department, Park City General Plan, Park City Municipal Corporation: Park City, pp. 11-19, 1997.

[11] The Planning Department, Park City's General Plan (Draft), Park City Municipal Corporation: Park City, pp. 165-168, 2013

[12] Williams-Blaes, D., Bowen Studios, Jameson, T., Guidelines for Historic Districts and Historic Sites Park City, Park City Municipal Corporation: Park City, pp. 4-15, 2009. 